\title{
Caracterização de Multicamadas de IN625 Depositadas por CMT
}

\author{
Hanna Carolina Bittencourt Pereira ${ }^{1}$, Sérgio Luiz Henke ${ }^{1}$, Ana Sofia Clímaco Monteiro D’Oliveira ${ }^{1}$ \\ 1 Universidade Federal do Paraná - UFPR, Departamento de Engenharia Mecânica, Curitiba, PR, Brasil
}

Recebido: 28 Nov., 2017

Aceito: 03 Jul., 2018

E-mails: hanna.mec16@gmail.com (HCBP), henke@ufpr.br (SLH), sofmat@ufpr.br (ASCMD)
Resumo: A manufatura aditiva é um processo utilizado na construção de peças com complexidade geométrica e no reparo de componentes mecânicos com alto valor agregado sendo portanto atrativa quando se utilizam materiais de elevado custo haja vista a menor necessidade de subtração de material. Nesse processo de deposição de multicamadas seguindo um modelo digital são produzidas estruturas mecânicas 3D. O sucesso de cada procedimento depende dos parâmetros de processamento, que incluem técnica de deposição, parâmetros, liga a ser depositada e condições da deposição. Controlar o efeito destes parâmetros nas propriedades é determinante para beneficiar o curto tempo de desenvolvimento do projeto na produção de peças. Neste contexto, diversos estudos têm sido desenvolvidos avaliando o efeito das multicamadas nas características dos componentes. Este trabalho vem contribuir para este tema após o processamento de multicamadas de uma liga a base de Ni (IN625) pelo processo MIG/MAG - CMT (Cold Metal Transfer). Amostras (paredes) de $15 \mathrm{~cm}$ de altura foram obtidas pela sobreposição de cordões e caracterizadas na condição como-depositada e após tratamento térmico de homogeneização. A influência da sobreposição das camadas na microestrutura e propriedades mecânicas foi avaliada por meio de medidas de dureza e ensaios de tração. O efeito dos múltiplos ciclos térmicos na microestrutura e nas propriedades mecânicas antes e após tratamento térmico foi também avaliado. Resultados mostraram que o tratamento térmico minimizou as heterogeneidades da microestrutura com multicamadas promovendo um aumento na resistência mecânica, porém, com queda da ductilidade quando comparado à amostra na condição como processada. A análise da região da fratura dos corpos-de-prova tracionados contribuiu para um melhor entendimento do efeito da deposição de multicamadas e posterior tratamento térmico.

Palavras-chave: Manufatura aditiva; IN625; Multicamadas.

\section{IN625 Multilayers Characterization Deposited by CMT}

\begin{abstract}
Additive manufacturing is a process used to build parts with geometric complexity, and repair technical components with high value added. The additive manufacturing has the advantage the capacity of producing components with complex geometry and less waste of material, fact which becomes attractive when working with high costs materials. In this multilayer deposition, process produces 3D mechanical structures following digital models. The success of each procedure depends of the processing of parameters, which is included technique of deposition, parameters, alloy to be deposited and conditions of deposition. Control the impacts of these parameters is determinant to obtain another advantage of this process that is the short time between the project development and the parts production. Many studies have been developed to evaluate the effects of the multilayers on the component. This study contributes to this discussion processing the Ni superalloy IN625 by GMAW-CMT (Cold Metal Transfer) process. Processed multilayers walls with $15 \mathrm{~cm}$ high were characterized as-deposited condition and after heat treatment. The impact of the multilayers on the microstructure and mechanical properties were evaluated by hardness and tensile test. The effects of the heat treatment on the mechanical properties are discussed. Results show that the heat treatment minimizes heterogeneities of the multilayer structure. After the heat treatment, occurred a decrease of ductility when compared to the wall as processed condition, besides that, exhibited a higher yield strength and tensile strength. The uniformity of the structure after heat treatment is confirmed by the lower dispersion of the results. Analysis of the fracture region contributed to a better understanding of the effects of multilayer deposition and subsequent heat treatment.
\end{abstract}

Key-words: Additive manufacturing; IN625; Multilayers.

\section{Introdução}

A manufatura aditiva (MA) é um processo de fabricação que consiste na construção de componentes por meio da sobreposição de várias camadas visando obter uma determinada geometria específica. Inicialmente a peça é modelada por software 3D a fim de obter um modelo o qual é composto de camadas visando definir a trajetória de deposição e,
Este é um artigo publicado em acesso aberto (Open Access) sob a licença Creative Commons Attribution Non-Commercial, que permite uso, distribuição e reprodução em qualquer meio, sem restriçōes desde que sem fins comerciais e que 0 trabalho original seja corretamente citado. 
portanto, a sequência de fabricação. As diferentes camadas são confeccionadas através da deposição de camada a camada por meio de um mecanismo de movimentação podendo este ser responsável não só pela alimentação do material, mas também como suporte da fonte de energia de processamento.

A manufatura aditiva é um dos processos que oferece novos caminhos para inovação e também oferece uma gama de vantagens logísticas, econômicas e tecnológicas. Dentre as vantagens que este processo apresenta, tem-se como exemplo a liberdade de design, fabricação de formas complexas, excelente relação "buy-to-fly", rápido tempo de fabricação e alta gama de materiais que podem ser utilizados. Com essa liberdade que o processo disponibiliza, a manufatura aditiva se enquadra em diferentes setores na indústria. Na indústria aeroespacial, componentes que têm a necessidade de serem leves e resistentes e de geometria complexa, fazem da manufatura aditiva um grande potencial de uso. Outro setor de possível aplicação do processo de MA é o setor automotivo, onde os veículos de luxo demandam aplicações de peças com alta complexidade geométrica além da possibilidade de personalizar veículos. Outras áreas de interesse são implantes médicos, ferramentaria e militar as quais possuem uma vasta gama de oportunidade para a aplicação desta técnica de fabricação.

Durante a fabricação de um componente por manufatura aditiva, algumas características são importantes para se obter sucesso durante o procedimento. Aspectos como a ligação metalúrgica entre o metal depositado e substrato, controle da morfologia dos cordões, ausência de defeitos e obtenção da microestrutura resultante, exigem conhecimento prévio sobre o processo a ser utilizado. Em operações de manutenção, por exemplo, a deposição do primeiro cordão é necessária requer uma boa ligação metalúrgica com o substrato, além de espessura e morfologia adequada para manutenção da geometria original. No caso da construção de componentes através da sobredeposição de múltiplas camadas é necessário o cuidado quanto à geometria, defeitos, morfologia e microestrutura. A morfologia, em geral, é analisada visualizando a continuidade dos cordões, variação de altura ou defeitos. A continuidade dos cordões está associada à seleção dos parâmetros de processamento, sendo que uma seleção inadequada pode resultar em cordões com grande variação de largura ou falta fusão do metal depositado [1].

Na manufatura aditiva podem ser utilizados materiais variados durante seu processo, como por exemplo, ligas de alumínio, titânio, aços, superligas, entre outros. Dentre estas possibilidades, há um grande destaque para as superligas. Estas superligas são ligas a base de Níquel ou Cobalto, com determinadas características mecânicas, químicas e físicas, tais como: resistência à corrosão, resistência à fluência e à fadiga. A liga base de Níquel, como a liga Inconel 625 (IN625) é utilizada para aplicações que requerem alta resistência à corrosão e elevada resistência mecânica. A temperatura de trabalho pode variar desde valores negativos até elevadas temperaturas como, por exemplo, em turbinas [2]. Para o processamento por manufatura aditiva da liga IN625, a deposição por LASER é a que apresenta maior abrangência [3]. Segundo estes autores, porém, há limitações quanto às baixas taxas de deposição e o alto custo de produção.

Neste contexto, o uso do processo MIG/MAG - CMT (Cold Metal Transfer), vem ser uma alternativa interessante. Tal processo baseia-se na deposição utilizando um sistema com curto-circuito controlado o qual propicia, segundo [4], a possibilidade de obtenção de uma poça fundida com maior viscosidade e a manutenção da mesma no lugar até a solidificação. Tal estabilidade da poça fundida, segundo estes autores, também favorece a soldagem em maiores velocidades. A liga IN625, no entanto, apresenta dificuldades associadas à molhabilidade utilizando processo CMT [5] o que em se tratando de manufatura aditiva, a princípio, pode ser benéfico do ponto de vista de obtenção de componentes estruturais de forma complexa.

Nas ligas a base de níquel endurecíveis por solução sólida, como a liga IN625, a estrutura cúbica de face centrada da matriz de níquel $(\gamma-\mathrm{Ni})$ pode ser endurecida por soluções sólidas de ferro, cromo, molibdênio, tungstênio, titânio e alumínio. Como o níquel não é um formador de carboneto, o carbono pode reagir com os elementos de liga, formando carbonetos do tipo $\mathrm{MC}, M_{6} C, M_{7} C_{3}$ e $M_{23} C_{6}$ (onde $\mathrm{M}$ é o metal formador de carbonetos) [6].

No sistema de liga Níquel-Cromo-Molibdênio (NiCrMo), a liga de Níquel IN625 recebe nióbio, um endurecedor da austenita por solução sólida, que em conjunto com o Molibdênio, resulta na formação de carbonetos. A presença do Nióbio também pode levar à formação da fase Laves responsável por trincas de liquação e de uma fase delta- $\delta$, um composto intermetálico acicular originado durante o tratamento térmico de alívio de tensões o qual resulta na queda da ductilidade e tenacidade da liga [7]. A grande quantidade de elementos de liga torna propícia a segregação desses elementos, podendo acarretar em trincas ou regiões com deficiência de algumas propriedades. Devido a isso é recomendado um tratamento térmico posterior à soldagem ou deposição, a fim de amenizar essa segregação de elementos e precipitar os compostos adequados [2]. 
A manufatura aditiva é um novo conceito de processo de fabricação se comparado aos meios tradicionais (conformação, fundição, etc.), oferecendo a facilidade de projetar componentes com geometrias que oferecem menor peso, recorrendo à fabricação pela deposição de multicamadas. Entretanto, esta nova abordagem exige, o controle dos parâmetros de deposição sobre a estrutura do material para poder alcançar as propriedades dos materiais. O presente trabalho se insere neste contexto e busca avaliar a viabilidade de obtenção de determinado componente por meio de multicamadas utilizando o processo MIG/MAG-CMT bem como avaliar sua integridade estrutural e comportamento mecânico nas condições como processado e após tratamento térmico.

\section{Materiais e Métodos}

A metodologia de análise consistiu na obtenção de duas amostras na forma de "paredes" resultantes da deposição de camadas de IN625 por meio de processo MIG/MAG CMT. Uma das amostras foi submetida a tratamento térmico de homogeneização e a outra foi analisada na condição como depositada. Ambas as amostras foram analisadas via microscopias óptica e eletrônica de varredura sendo suas propriedades mecânicas determinadas por meio de ensaio de tração e dureza.

As multicamadas foram depositadas com o processo MIG/MAG CMT sobre um substrato de aço inoxidável AISI 304. O sistema utilizado para a deposição incluiu um equipamento CMT, sendo o mecanismo responsável pela condução do arame um braço robótico. Foi utilizado um arame de IN625 com 0,89 mm de diâmetro sendo a deposição efetuada com tecimento. A Tabela 1 e a Figura 1 apresentam demais condições utilizadas e uma das amostras obtida com as respectivas dimensões.

Tabela 1. Parâmetros do processo MIG/MAG CMT1638 utilizado para a confecção das paredes.

\begin{tabular}{cc} 
Parâmetro & Valor \\
Tensão & $12,8 \mathrm{~V}$ \\
Corrente & $131 \mathrm{~A}$ \\
Velocidade de alimentação arame & $7,7 \mathrm{~m} / \mathrm{min}$ \\
Velocidade longitudinal & $2,5 \mathrm{~mm} / \mathrm{s}$ \\
Velocidade transversal & $6,0 \mathrm{~mm} / \mathrm{s}$ \\
Gás utilizado & $\mathrm{Ar}-2 \% \mathrm{O}_{2}$ \\
\hline
\end{tabular}
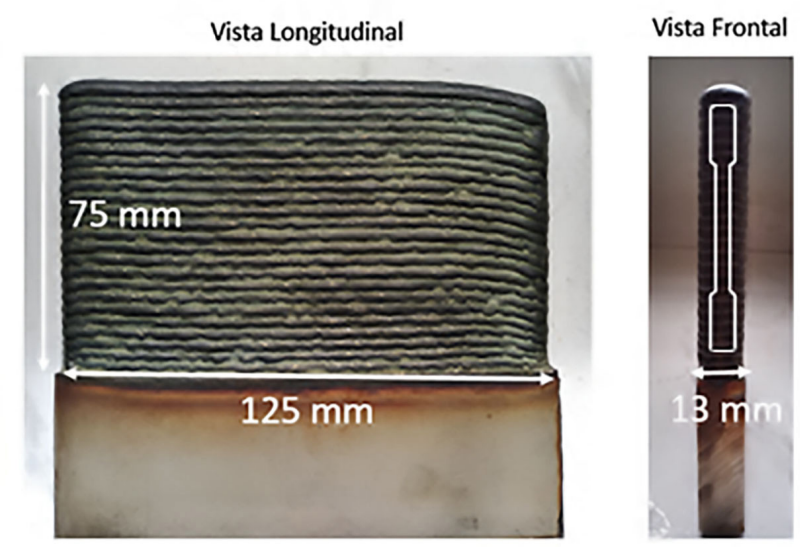

Figura 1. Parede de IN625 obtida por manufatura aditiva contendo dimensões e posicionamento do corpo-de-prova para realização do ensaio de tração.

O tratamento térmico de homogeneização aplicado em uma das paredes e foi conduzido em forno mufla na temperatura de $1000^{\circ} \mathrm{C}$ por um período de 8 horas. Na sequência, o forno foi desligado e a amostra permaneceu no interior até a temperatura ambiente. 
Para determinação das propriedades mecânicas das paredes com multicamadas na condição como depositada e com tratamento térmico, foram retirados corpos-de-prova posicionados verticalmente em relação às deposições sendo que a espessura da parede das amostras correspondia à largura da cabeça dos corpos-de-prova (Figura 1). Os corpos-de-prova foram ensaiados em máquina de tração marca EMIC com capacidade de até $30 \mathrm{kN}$. Depois de ensaiados as superfícies fraturadas dos corpos-de-prova foram avaliadas com auxílio de microscópio eletrônico de varredura (MEV).

Em paralelo, visando identificar as fases presentes, bem como a distribuição dos elementos químicos nas amostras, foram efetuadas análises metalográficas por meio de microscopia óptica (MO) e MEV das seções transversais das camadas. Para as análises dos elementos químicos via MEV foram utilizados detectores de elétrons retroespalhados (BSE) e de energia dispersiva de raios-x (EDS). A revelação da microestrutura foi efetuada por meio de ataque químico utilizando as soluções de Glyceregia e Nital $5 \%$ sendo o primeiro por imersão e o segundo por meio eletrolítico utilizando tensão de $4 \mathrm{~V}$ durante $15 \mathrm{~s}$.

Medidas de microdureza Vickers $\left(\mathrm{HV}_{0,3}\right)$ foram também realizadas sobre os corpos de prova metalográficos. As indentações foram efetuadas ao longo da seção transversal da penúltima camada depositada em ambas as paredes de multicamadas. Considerou-se que, exceto a primeira e a última camada, as demais apresentem similaridade em termos de perfil de dureza.

\section{Resultados e Discussão}

Neste item serão apresentados os resultados bem como discussões do efeito das multicamadas e do tratamento térmico aplicado nas propriedades mecânicas e na microestrutura das multicamadas. Destaca-se que o processamento de componentes por multicamadas induz à formação de interfaces a cada camada depositada, o que pode criar heterogeneidades na estrutura, somado a este efeito cada camada depositada impõe um ciclo térmico e está exposta a diversos ciclos térmicos associados a deposições posteriores das outras camadas a medida que a parede vai sendo produzida. Neste contexto é relevante identificar como a fabricação por multicamadas afeta microestrutura e propriedades mecânica de resistência e ductilidade e como o tratamento térmico a pós deposição impacta nestas propriedades e microestrutura

\subsection{Efeito nas propriedades mecânicas}

As propriedades mecânicas das multicamadas na condição como depositada, ou seja, sem tratamento térmico (S/TT) são apresentadas na Tabela 2. É possível identificar o pequeno desvio padrão medido na determinação da resistência e ductilidade, sugerindo uma uniformidade da estrutura ao longo das paredes multicamadas.

Tabela 2. Propriedades mecânicas obtidas no ensaio de tração no material como depositado, ou seja, sem tratamento térmico (S/TT).

\begin{tabular}{ccccc}
\hline & $\begin{array}{c}\text { Limite de Resistência } \\
\text { a Tração (MPa) }\end{array}$ & $\begin{array}{c}\text { Tensão de } \\
\text { Escoamento (MPa) }\end{array}$ & Alongamento (\%) & Redução de Área (\%) \\
CP1 & 664,9 & 411 & 56,8 & 44,5 \\
CP 2 & 645,4 & 401,7 & 50,1 & 38,9 \\
CP 3 & 641,6 & 405,9 & 58,1 & 42,9 \\
Média & $\mathbf{6 5 5 , 2}$ & $\mathbf{4 0 6 , 2}$ & $\mathbf{5 3 , 5}$ & $\mathbf{4 2 , 1}$ \\
Desvio Padrão & $\mathbf{1 2 , 5}$ & $\mathbf{3 , 2}$ & $\mathbf{3 , 5}$ & $\mathbf{2 , 9}$ \\
\hline
\end{tabular}

Uma melhor contextualização destes valores é conseguida comparando com dados da literatura para a liga IN625 em diversas condições de processamento [2]. Constata-se que a liga IN625 processada por MA se assemelha em suas propriedades ao material trabalhado e recozido (barra) que exibe Tensão de Escoamento de $414 \mathrm{MPa}$ e um Alongamento de até $60 \%$. Por outro lado, o material processado por MA apresenta um Limite de Resistência à Tração de $655 \mathrm{MPa}$ enquanto que a liga IN 625 trabalhada e recozida apresenta um limite variando de 827 a $1034 \mathrm{MPa}$, ou seja, o processo de MA apresentou um comprometimento da tensão máxima o que pode ser associado com a estrutura fundida em oposição a estrutura de grãos equiaxiais da barra recozida a qual exibe uma maior uniformidade da estrutura. 
Resultados de tração medidos após tratamento térmico (C/TT) das multicamadas são apresentados na Tabela 3. Constata-se um aumento aproximado de $10 \%$ na resistência do material em relação à condição como depositada, acompanhado por uma redução nas características de ductilidade.

Tabela 3. Propriedades mecânicas obtidas no ensaio de tração no material com tratamento térmico (C/TT).

\begin{tabular}{|c|c|c|c|c|}
\hline & $\begin{array}{l}\text { Limite de Resistência } \\
\text { a Tração (MPa) }\end{array}$ & $\begin{array}{c}\text { Tensão de } \\
\text { Escoamento }(\mathrm{MPa})\end{array}$ & Alongamento (\%) & Redução de Área (\%) \\
\hline $\mathrm{CP} 1$ & 714,5 & 424,9 & 45 & 25,8 \\
\hline $\mathrm{CP} 2$ & 700,9 & 429,2 & 47,6 & 27,6 \\
\hline $\mathrm{CP} 3$ & 713,6 & 431,3 & 49,8 & 22 \\
\hline Média & 709,7 & 428,5 & 47,5 & 25,1 \\
\hline Desvio Padrão & 6,2 & 3,2 & 2,4 & 2,9 \\
\hline
\end{tabular}

A influência do tratamento térmico no comportamento a tração das multicamadas está resumida nas Figuras 2(a) e (b) que compara o comportamento apresentado na condição como depositada e após tratamento térmico. São apresentados os limites máximo e mínimo medidos para cada condição. É interessante destacar a menor dispersão de resultados, menor desvio padrão, sugerindo que ocorreram alterações na estrutura responsáveis por uma maior uniformidade e um aumento da resistência mecânica.

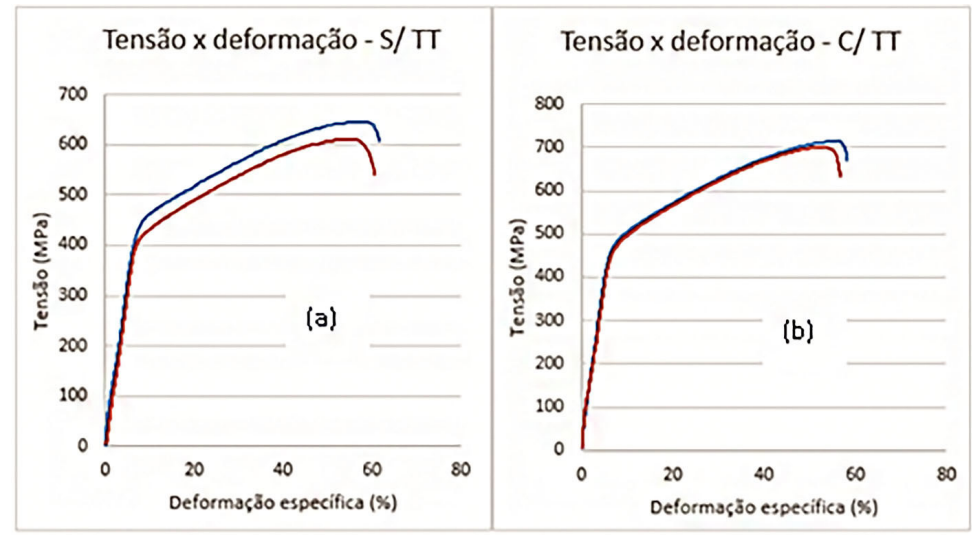

Figura 2. Dispersão de curvas tensão x deformação sem (a) e com tratamento térmico (b). Curvas em vermelho e azul representam os valores mínimos e máximos respectivamente obtidos nos ensaios de tração.

A análise do comportamento mecânico das paredes multicamadas na condição como processadas e após tratamento térmico incluiu a análise das características da ruptura dos corpos de prova, Figura 3. É identificada a característica de comportamento dúctil. A fratura dúctil é caracterizada por apresentar uma deformação plástica substancial com uma grande absorção de energia até a sua fratura. Este processo de fratura se resume em duas etapas, compreendendo a formação e propagação de trinca em relação ao esforço que o material é submetido ao ser realizado o ensaio de tração [8]. Normalmente, estes materiais apresentam uma estricção até o ponto de sua fratura, resultando em um perfil da superfície de ruptura denominado "taça e cone". Observa-se que na condição como processada a estricção na região de fratura é bem mais significativa, como já indicado, na análise quantitativa (redução de área).

A análise da superfície de fratura dos corpos-de-prova tracionado por MEV (Figura 4), revelou em ambas as condições estudadas a presença de microcavidades esféricas ("dimples"), característica típica de uma fratura dúctil. As superfícies fraturadas não revelaram a existência de defeitos de soldagem que pudessem ter influenciado nos resultados, corroborando assim com a pouca dispersão das medidas realizados no ensaio de tração. Observação detalhada dos resultados da análise das superfícies de fratura dos corpos de prova após tratamento térmico, levanta 

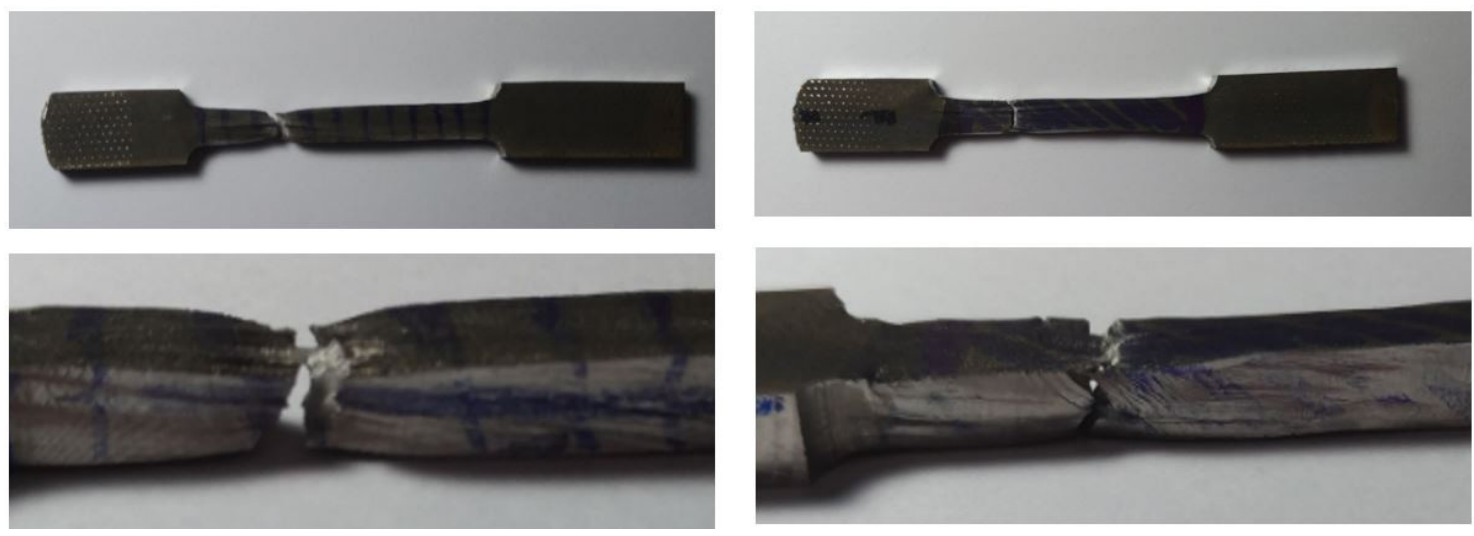

Figura 3. Aspecto geral dos corpos-de-prova com e sem tratamento térmico após ruptura no ensaio de tração.

(a)

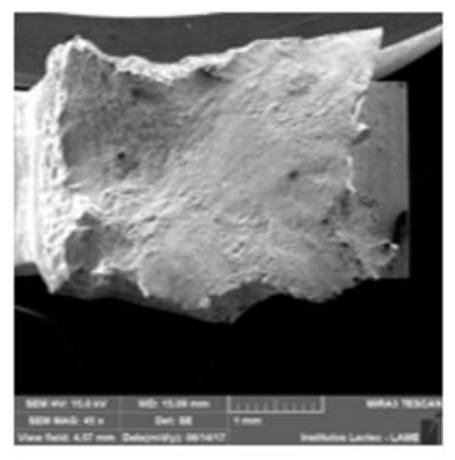

(b)

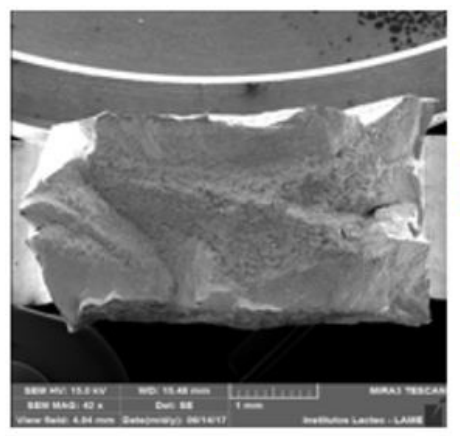

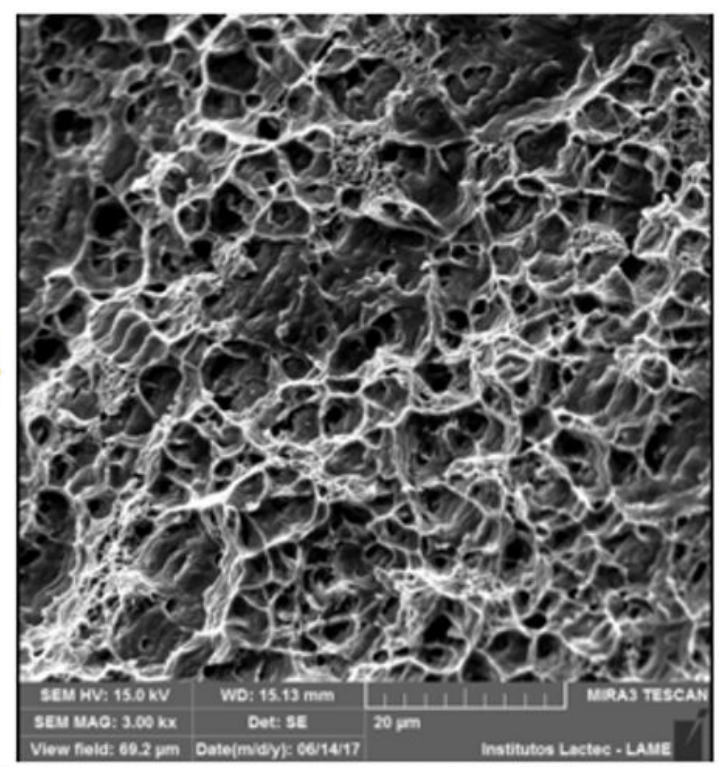

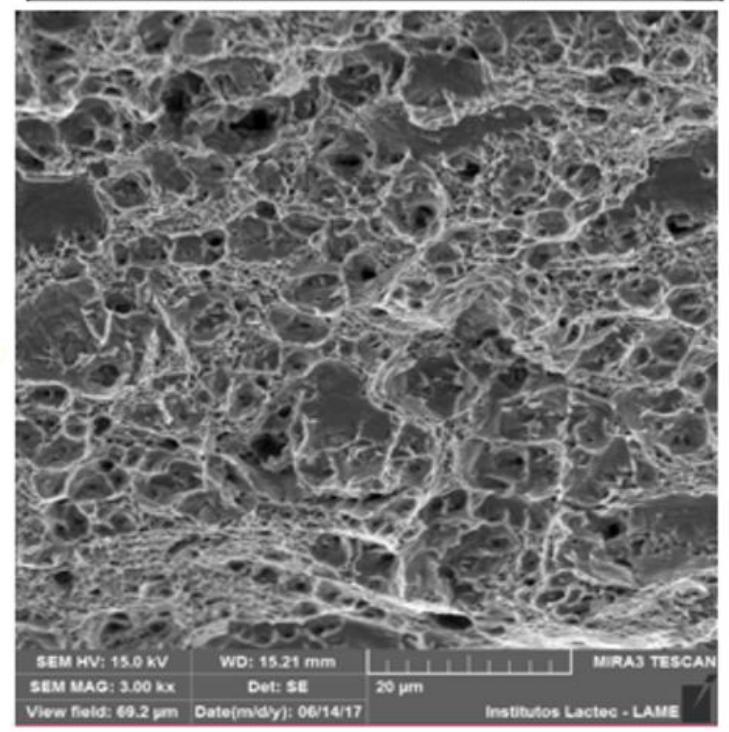

Figura 4. Análise fractográfica dos materiais via MEV após ensaio de tração (a) sem tratamento térmico (b) com tratamento térmico. Presença de microcavidades "dimples" típicas de fratura dúctil. 
a possibilidade da presença de partículas que possam atuar como concentradores de tensão, o que justificaria a maior dispersão de resultados e a menor estricção apresentada pelos corpos de prova após teste de tração.

Complementando a análise das características mecânicas foram obtidos perfis de dureza medidos na seção transversal de um cordão no meio da parede de multicamadas nas condições como depositado e após tratamento térmico, Figura 5.

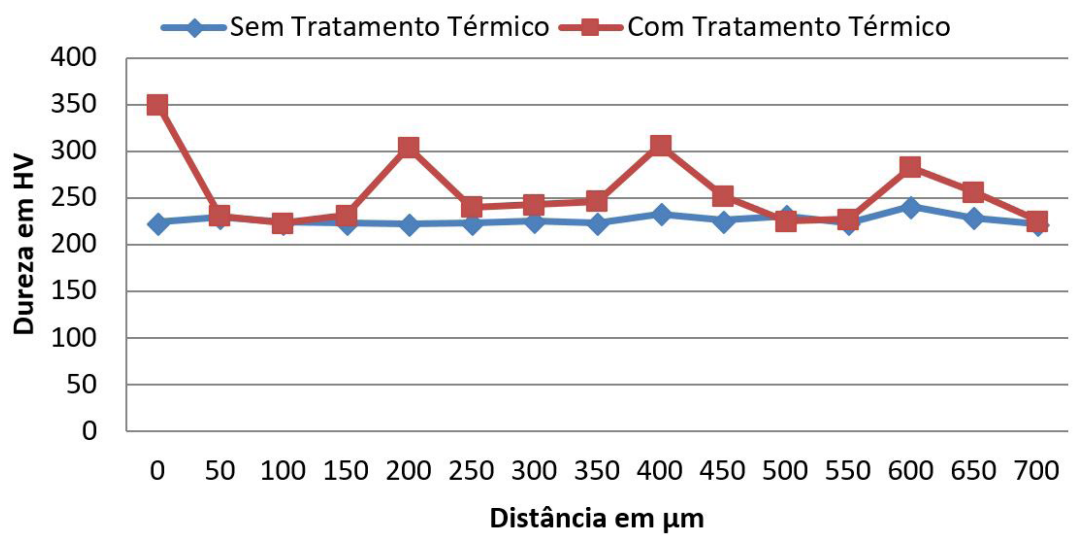

Figura 5. Perfis de dureza obtidos ao longo da camada nos materiais com e sem tratamento térmico.

Na condição como depositada foi medida uma dureza média de 226 HV, com desvio padrão de 5 HV, ou seja, inferior a 5\%, confirmando os resultados dos testes de tração de que não há variações significativas no decorrer das camadas. Correlacionando com as especificações encontradas na literatura, a dureza do material processado pela Manufatura Aditiva apresenta um valor semelhante à liga na condição trabalhada e recozida de em torno 222 HV [2].

É possível identificar que após tratamento térmico ocorre uma maior variação da dureza na seção transversal da camada, que exibe picos com um espaçamento cíclico. Em consequência, ocorre um aumento da dureza média em relação à condição como depositada de 226 HV para 256 HV após tratamento térmico. Esta variação de dureza medida na seção transversal de uma camada pode estar associada à formação de fases de maior dureza como carbonetos e delta.

\subsection{Caracterização microestrutural}

Complementado a avaliação das propriedades mecânicas das paredes construídas a partir da deposição de multicamadas, foi caracterizada a microestrutura.

Na avaliação das duas paredes de multicamadas processadas não foram constatadas trincas, sejam estas de solidificação ou liquação. Segundo [7] a ocorrência de trincas de solidificação na liga IN625 estaria associada ao formato do cordão depositado, ou seja, cordões com formato levemente convexo teriam menor probabilidade de trincas. Com relação às trincas de reaquecimento estes mesmos autores destacam que a tendência de tais trincas aumenta com processos de soldagem com aporte de calor elevado como, por exemplo, MIG/MAG spray. Desta forma, a nosso ver, a baixa molhabilidade e o menor aporte do processo MIG/MAG CMT vem a justificar a ausência de tais trincas.

As Figuras 6 e 7 ilustram a microestrutura das multicamadas na condição como depositada. Se observa uma estrutura de solidificação de dendritas de austenita a base de $\mathrm{Ni}$ ( $\gamma$-Ni) com orientação cristalográfica determinada pela a direção do escoamento do calor durante a deposição [9]. Esta direção preferencial de solidificação da estrutura é oposta ao sentido do fluxo de calor em função do gradiente máximo de temperatura. É interessante observar que A deposição das multicamadas da liga IN 625 favorece o crescimento epitaxial das dendritas que se desenvolvem na mesma orientação cristalográfica daquelas solidificadas na camada anterior, podendo este fenômeno resultar em dendritas que se formam ao longo de várias camadas. Tal orientação apresenta certo ângulo em relação ao 


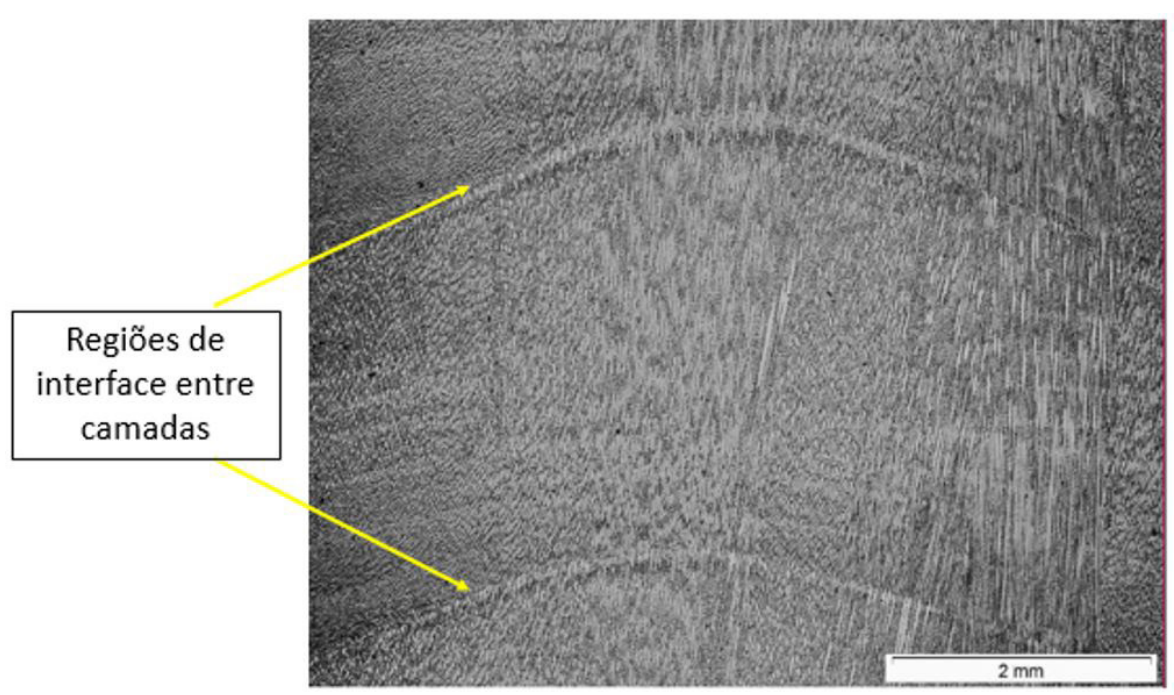

Figura 6. Microestrutura colunar dendrítica do material na condição como depositado indicando interface entre camadas.

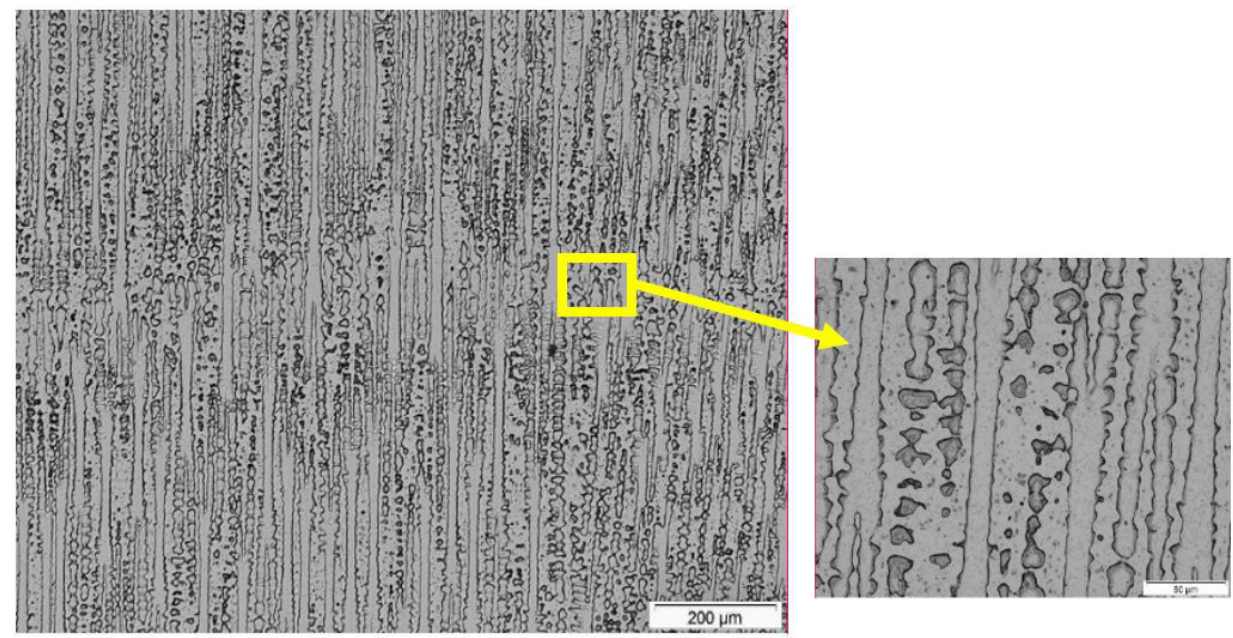

Figura 7. Microestrutura colunar dendrítica do material na condição como depositado revelando segregação interdendrítica.

eixo perpendicular das multicamadas haja vista o crescimento dendrítico originar a partir da superfície curva dos cordões anteriormente depositados. Interessante observar ainda na análise da seção transversal a interface entre camadas depositadas é bem marcada, estando associada à zona parcialmente fundida resultante das deposições subsequentes. Além destas interfaces, são constatadas bandas no interior dos cordões decorrentes da solubilização parcial dos elementos segregados (regiões menos atacadas pelo reativo metalográfico). Tal solubilização é decorrente dos ciclos térmicos oriundos das deposições subsequentes. Destaca-se que tais bandas apresentam pouca espessura o que indica uma limitada difusão dos elementos segregados.

Maior detalhamento da microestrutura é apresentado na Figura 7 que destaca a segregação interdendrítica que leva a concentração diferenciada dos elementos na região entre as dendritas.

Análise da estrutura após tratamento térmico em microscópio óptico permite identificar ainda, de forma menos contrastante, a estrutura colunar dendrítica, assim como as regiões de interface entre camadas, Figura 8. 


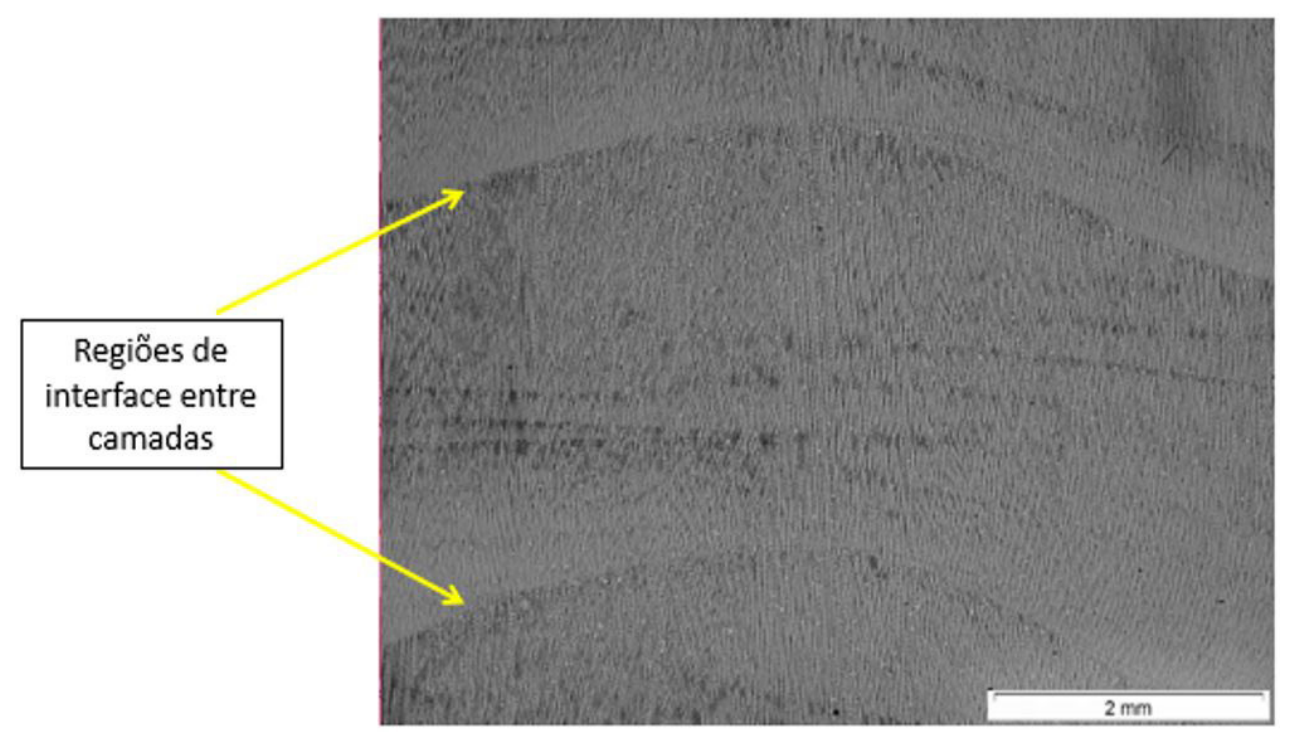

Figura 8. Microestrutura colunar dendrítica do material com tratamento térmico.

O detalhamento da estrutura apresentado na Figura 9 permite distinguir a resposta da estrutura das multicamadas ao tratamento térmico quando comparada à sua microestrutura na condição como depositado. É possível identificar que a segregação na região interdendrítica foi substituída após tratamento térmico por uma fina dispersão de precipitados.

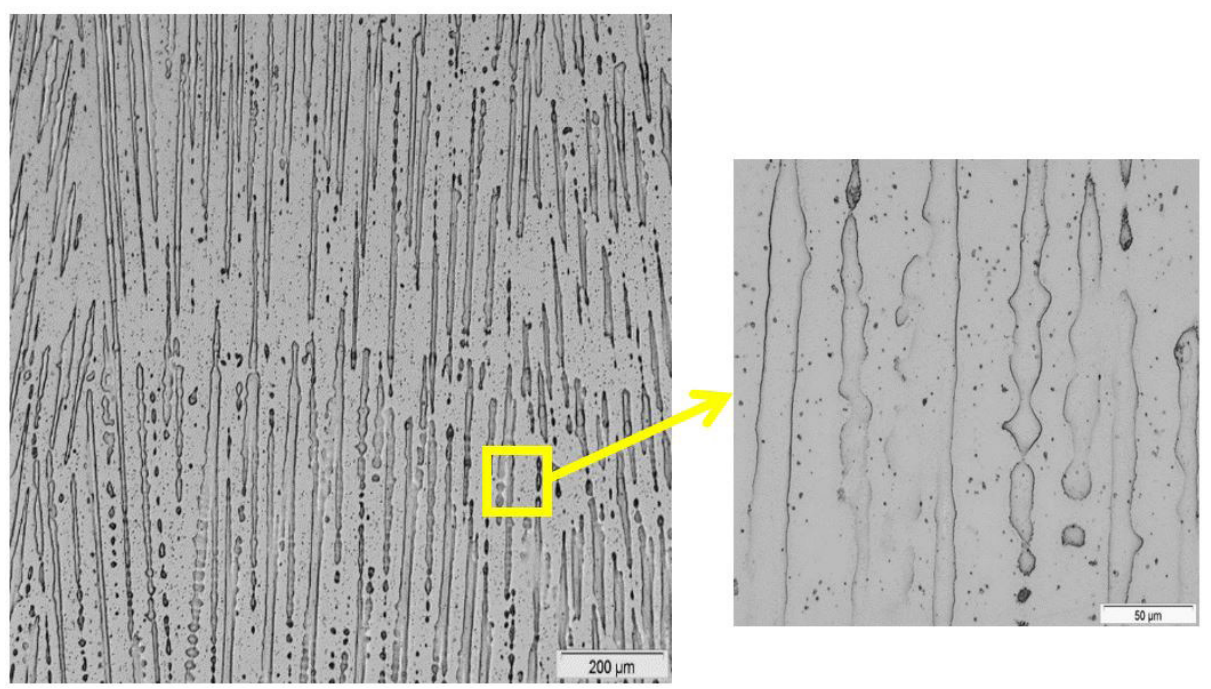

Figura 9. Microestrutura revelando colunas dendríticas do material com tratamento térmico.

Complementando a análise por microscopia ótica, a Figura 10 apresenta um comparativo entre as paredes de multicamadas na condição como depositada e após tratamento térmico observadas via MEV, (modo BSE - elétrons retroespalhados) onde se constata praticamente a homogeneização da estrutura em termos de composição química. Na condição como depositada são identificados pontos e áreas com tonalidade mais clara característicos da presença de elementos de maior peso atômico como Nb e Mo distribuídos entre as dendritas. De acordo com Li et al. [10] esta microestrutura contrasta com aquelas descritas na literatura quando da utilização de processos de 
deposição de maior densidade de energia, como é o caso de deposições de IN625 utilizando LASER, em que estes elementos tendem a permanecer em solução sólida na matriz de níquel devido à alta taxa de resfriamento (cerca de $10^{6} \mathrm{~K} / \mathrm{s}$ ). Um rearranjo dos elementos de liga ocorre após tratamento térmico como se observa na figura $10 \mathrm{~b}$, se observa a quase total a eliminação de tais áreas claras após a realização do tratamento térmico permanecendo, porém, a presença isolada dos pontos claros.

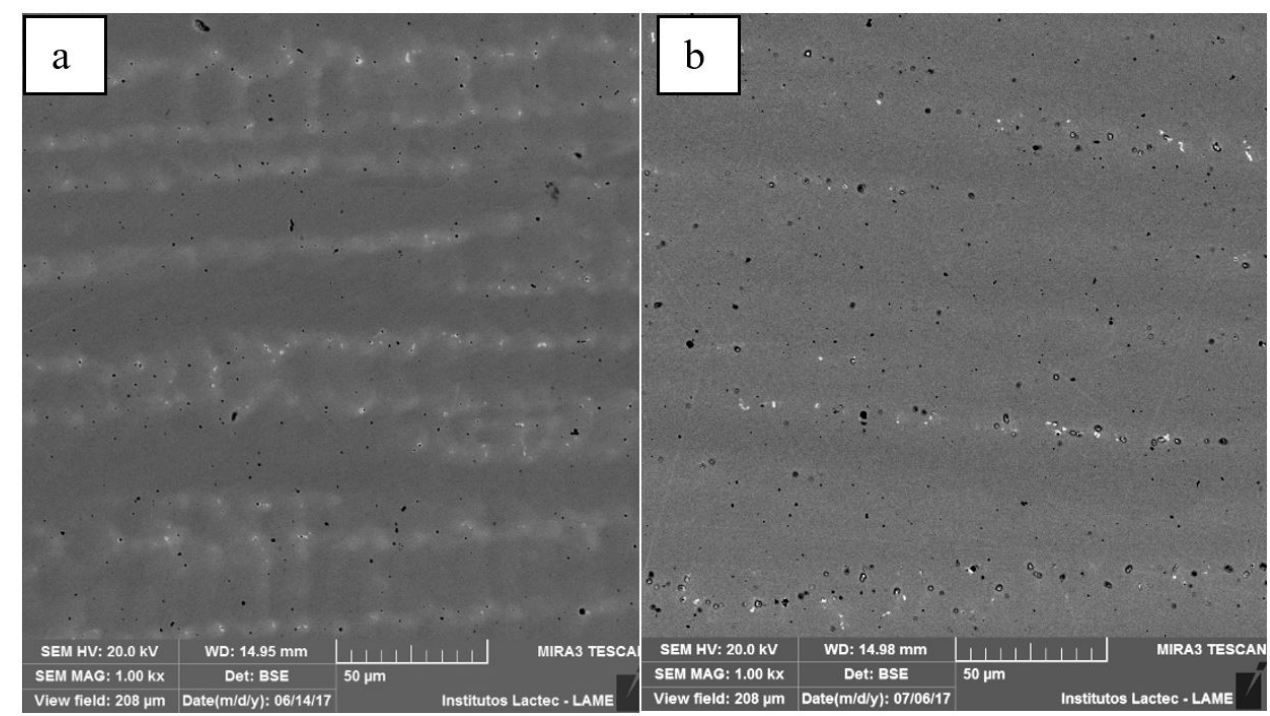

Figura 10. Microestrutura observada por microscopia eletrônica por varredura - BSE do material sem tratamento térmico em (a) em comparação ao tratado termicamente em (b).

A análise detalhada destes pontos, Figura 11, mostra a presença de partículas maiores arredondadas e em torno destas uma rede de partículas aciculares. A análise por EDS realizada sobre tais regiões (Figura 12 e Tabela 4) revela a presença de $\mathrm{Nb}$, Mo e C o que caracteriza a formação da fase de Laves, carbetos e da fase $\delta$ (delta) durante o tratamento térmico. A presença da fase delta, como já citado anteriormente, não é desejada, pois resulta na redução da tenacidade e ductilidade do material.
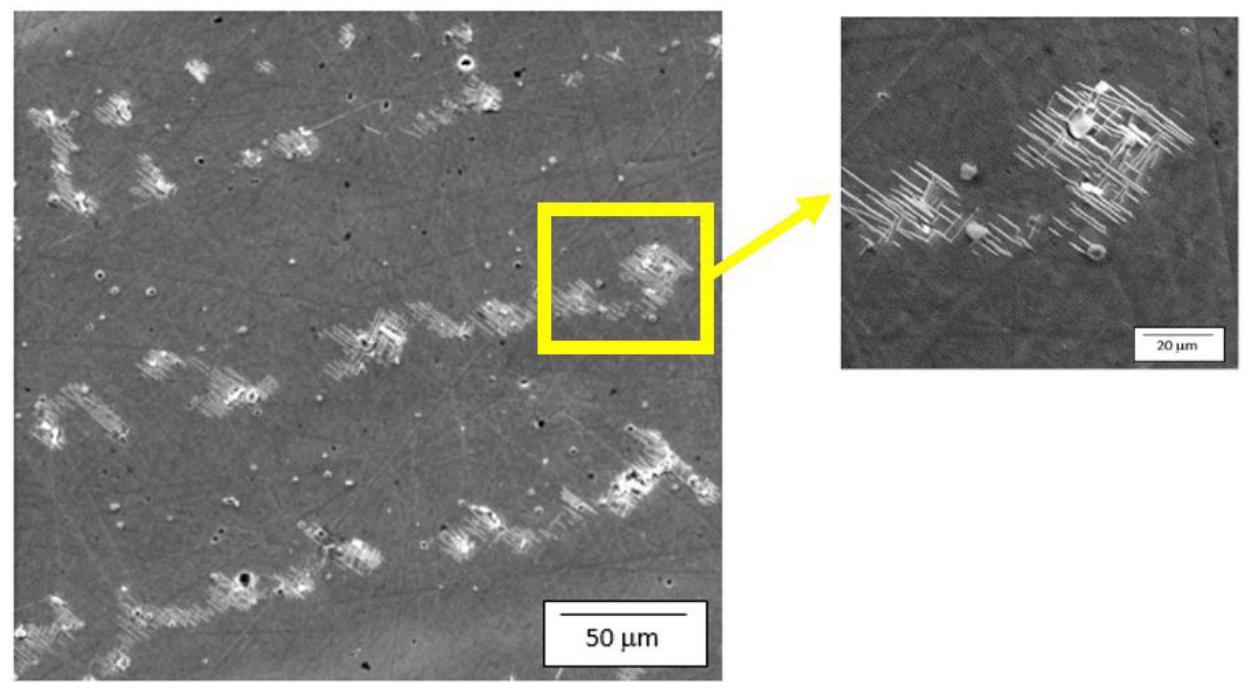

Figura 11. Imagem por microscopia eletrônica por varredura do material tratado termicamente indicando a presença de carbetos e da fase $\delta$. 

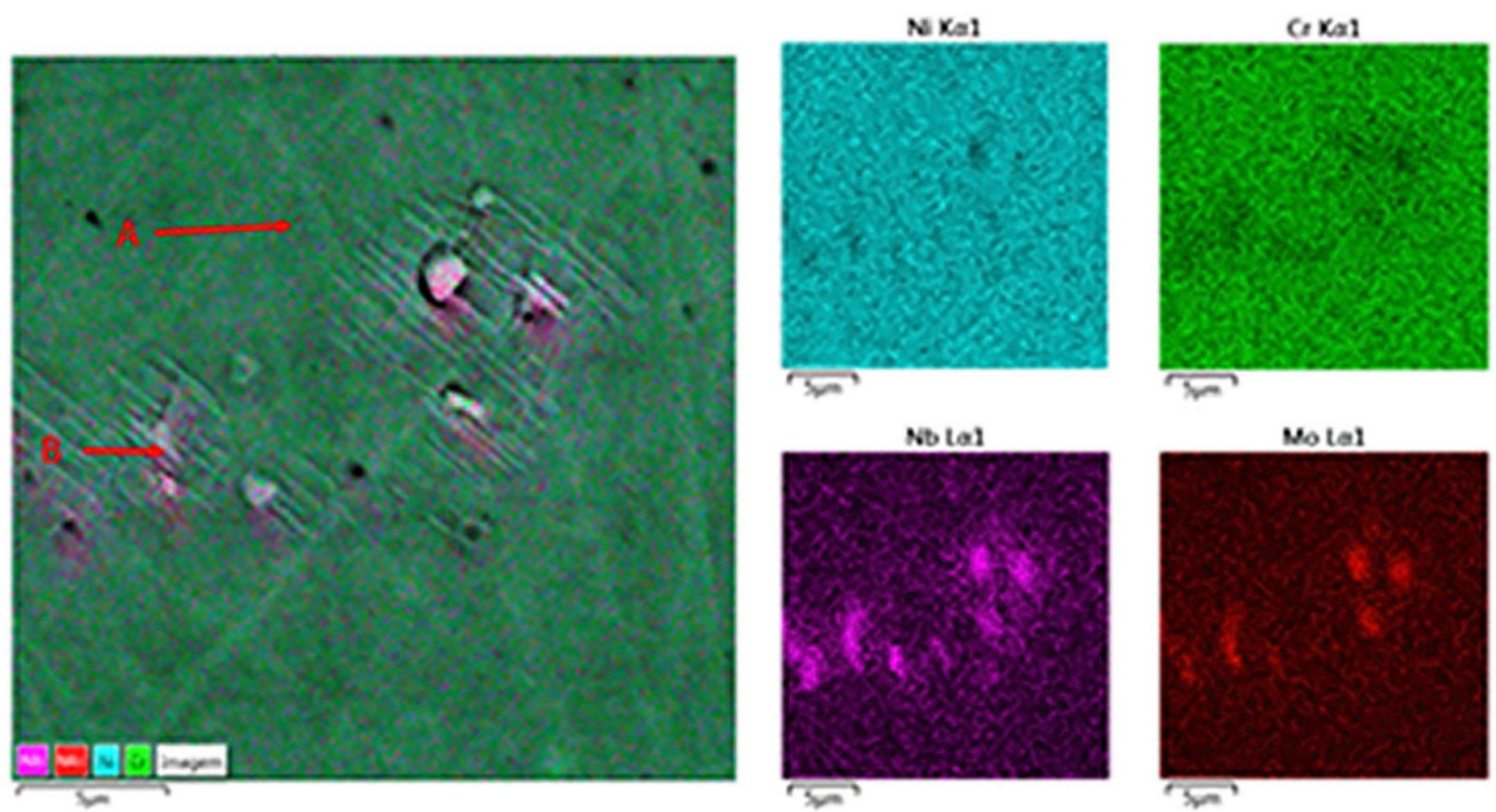

Figura 12. Micrografia SEM do material como depositado e mapas de distribuição dos elementos $\mathrm{Ni}$, Nb, $\mathrm{Cr}$ e Mo.

Tabela 4. Análise de EDS dos elementos nos pontos A e B da Figura 8.

\begin{tabular}{ccccccc}
\hline Ponto & Ni & Cr & Mo & C & Nb & Fe \\
A & 61,8 & 22 & 8,5 & - & 3,3 & 0,3 \\
B & 63,4 & 22,2 & 9,4 & 4,1 & 4,7 & 0,3 \\
\hline
\end{tabular}

\section{Conclusões}

Para as condições de teste deste trabalho que avaliou o efeito da deposição de multicamadas nas características da liga IN625 é possível destacar:

- O processo MIG/MAG-CMT mostrou-se capaz de constituir a peça final através de deposição de multicamadas utilizando liga IN625;

- Além da alta performance com relação à deposição, tal processo não apresentou a formação de trincas de solidificação bem como trincas de liquação;

- A ausência de trincas de solidificação estaria associada a uma maior convexidade dos cordões depositados enquanto que as trincas de liquação à baixa energia de deposição, ambas comparadas à processos MIG/MAG de maior energia;

- De maneira geral, a microestrutura consiste na formação colunar dendrítica seguindo um crescimento epitaxial de acordo com a direção de fluxo de calor apresentando ainda segregações de $\mathrm{Nb}$ e Mo em regiões interdendríticas;

- Com o tratamento térmico, percebe-se uma maior homogeneização da microestrutura do material, o que permite uma menor dispersão da resposta do material durante ensaios mecânicos. Através dos resultados obtidos nestes ensaios, concluiu-se que o material apresenta uma maior tensão de escoamento, limite de resistência à tração e dureza, mas em contrapartida uma menor ductilidade resultante da formação de fase delta. 


\section{Referências}

[1] Martina F, Mehnen J, Williams SW, Colegrove P, Wang F. Investigation of the benefits of plasma deposition for the additive layer manufacture of Ti-6Al-4V. Journal of Materials Processing Technology. 2012;212(6):1377-1386. http://dx.doi. org/10.1016/j.jmatprotec.2012.02.002.

[2] Special Metals. INCONEL alloy 625. New Hartford: Special Metals Corporation; 2013 [Acesso em 26 jul. 2018]. Disponível em: http://www.specialmetals.com/assets/smc/documents/ alloys/inconel/inconel-alloy-625.pdf

[3] Xu F, Lv Y, Liu Y, Shu F, He P, Xu B. Microstructural evolution and mechanical properties of Inconel 625 alloy during pulsed plasma arc deposition process. Journal of Materials Science and Technology. 2013;29(5):480-488. http://dx.doi.org/10.1016/j. jmst.2013.02.010.

[4] Scotti A, Ponomarev V. Soldagem MIG/MAG: melhor entendimento, melhor desempenho. São Paulo: Artliber Editora; 2008.

[5] Dutra JC, Silva RHG, Marques C, Viviani AB. A new approach for MIG/MAG cladding with Inconel 625 . Welding in the World.
2016;60(6):1201-1209. http://dx.doi.org/10.1007/s40194-0160371-3.

[6] Asm Handbook. Properties and selection: nonferrous alloys and special- purpose materials, Vol. 2. Russell Township: ASM International; 1992. p. 1363-1403.

[7] John ND. Welding metallurgy and weldability of nickel-base alloys. 1st ed. New Jersey: John Wiley \& Sons; 2009. 93 p.

[8] Wulpi DJ. Understanding how components fail. 2nd ed. Russell Township: ASM International; 1999.

[9] Wang JF, Sun QJ, Wang H, Liu JP, Feng JC. Effect of location on microstructure and mechanical properties of additive layer manufactured Inconel 625 using gas tungsten arc welding. Materials Science and Engineering A. 2016;676:395-405. http:// dx.doi.org/10.1016/j.msea.2016.09.015.

[10] LiS, Wei Q, Shi Y, Zhu Z, Zhang D. Microstructure characteristics of Inconel 625 superalloy manufactured by selective laser melting. Journal of Materials Science and Technology. 2015;31(9):946952. http://dx.doi.org/10.1016/j.jmst.2014.09.020. 